\title{
The Comparison of Silver and Hydroxyapatite Nanoparticles Biocompatibility on L929 Fibroblast Cells: An In vitro Study
}

Hossein Shahoon ${ }^{1}$, Roya Hamedi ${ }^{2}$, Zahra Yadegari ${ }^{3 *}$, Vahid Al Majd Hosseiny ${ }^{4}$, Pantea Golgounnia ${ }^{5}$ and Sogol Amiri ${ }^{6}$

${ }^{1}$ Assistant professor, Department of Oral and Maxillofacial Surgery, Dental Faculty, Shahed University, Tehran, Iran

${ }^{2}$ Dental student, Dental faculty, Shahed University, Tehran, Iran

${ }^{3}$ M.S of Cellular and Molecular Biology, Dental Faculty, Shahid Beheshti University of Medical Sciences, Tehran, Iran

${ }^{4} D D S$, Shiraz, Iran

${ }^{5} D D S$, Tehran, Iran

${ }^{6}$ Dental student, Dental faculty, Shahed University, Tehran, Iran

\begin{abstract}
Background and aims: Nano particles are tiny materials $(<1000 \mathrm{~nm}$ in size $)$ that have specific physicochemical properties different to bulk materials of the same composition and such properties make them very attractive for commercial and medical development. In contrast to many efforts aimed at exploiting desirable properties of nano particles for medicine, there are limited attempts to evaluate potentially undesirable effects of these particles. Therefore, there is a pressing need for careful consideration of benefits and side effects of the use of nano particles in medicine. The purpose of this research was to compare the nano silver and hydroxyapatite nanoparticles' biocompatibility on L929 fibroblast cells.
\end{abstract}

Materials and methods: To evaluate the biocompatibility of nano silver and hydroxyapatite nanoparticles (nHA), L929 fibroblast cells were cultured on a 96-well plate. Cells were exposed to nHA and nano silver at the following concentrations: 5, 10, 20, 30, 40, $50 \mathrm{ppm}$ after 24,48 and $72 \mathrm{hrs}$. Later, for measuring the biocompatibility of materials, MTT method was utilized.ANOVA test was used for statistical analysis.

Results: None of the $\mathrm{nHA}$ experimented concentrations were toxic, but vitality of cells exposing to nano silver particles were the least after 24 hours and increased after 48 hours and ANOVA analyze indicated that there was significant difference between groups $(p<0.05)$. Also the result showed nano silver particles at concentrations more than $20 \mathrm{ppm}$ within 24 and 48 hours are toxic to fibroblast cells and it was significant $(p<0.02)$.

Conclusion: NHA were more biocompatible rather than nano silver particles on L929 fibroblast cells.

Keywords: Hydroxyapatite nano particles; Nano silver; L929 fibroblast cells; Cytotoxicity; Photo absorption

\section{Introduction}

Nanotechnology is the understanding and control of matter at dimensions of roughly 1-100 nanometers, where unique phenomena enable novel applications $[1,2]$. In the last decade, engineered nano particles have become an important class of new materials with several properties that make them very attractive for researchers $[3,4]$. Nano silver and hydroxyapatite nano particles are the most used of these compounds [5,6]. Antimicrobial effects of silver, has been known for long time but after it has been developed as nano-particles [7-9], the contact surfaces have been increased and its antimicrobial effects have been improved more than $99 \%$ and because of its substantial antibacterial, anti viral and anti fungal effects, its uses has been strongly approved in medicine $[10,11]$. Also, nHA has been introduced for augmentation procedures in osseous defects [8-11]. The nHA particles has already been used for treatment of human periodontal bony defects $[12,13]$ and various types of metaphyseal fractures such as the calcaneus and tibia in orthopedic surgery [14], as well as tooth perforations [15], jaw cysts [16], and peri implantitis lesions $[17,18]$, also nHA particles are currently being investigated to be used as delivery vehicles in various medical applications, including the delivery of growth factors antibiotics [19], anticancer drugs [20]. Despite of wide spread use of nanosilver and nHA there is no enough studies about its side effects on human $[21,22]$. Degradation products of nano materials are potentially toxic $[23,24]$. Thus, it is essential to assess biocompatibility of these materials before their usage in clinical applications. The purpose of this research was to compare the nano silver and hydroxyapatite nanoparticles' biocompatibility on L929 fibroblast cells by using the MTT assay.

\section{Materials and Methods}

\section{Preparation and sterilization of $\mathrm{nHA}$ and nano silver particles}

In this study, nano sized, rod- like hydroxyapatite particles (Figure 1) and spherical nano silver particles (Figure 2) provided from NANOSHEL corporation (Batch No\#290090621 and 280080521 respectively) and were precisely sterilized by UV for $24 \mathrm{hrs}$.

\section{Preparation and culture of L929 fibroblast cells}

Murine L929 fibroblast cells were prepared from Iran-Pastoor institute, after defreezing the cells, they were stored in special flasks. Microscopic image of L929 fibroblast cells were cultured in flasks was shown in figure 3. We have used DMEM (Grand Island, NY) medium,

*Corresponding author: Zahra Yadegari, M.S of Cellular and Molecular Biology, Dental Faculty, Shahid Beheshti University of Medical Sciences, Tehran, Iran, Tel: +982188959210; Fax: +982188967618; E-mail: zahrayadegari24@yahoo.com

Received March 27, 2013; Accepted May 20, 2013; Published May 22, 2013

Citation: Shahoon H, Hamedi R, Yadegari Z, Majd Hosseiny VA, Golgounnia $P$, et al. (2013) The Comparison of Silver and Hydroxyapatite Nanoparticles Biocompatibility on L929 Fibroblast Cells: An In vitro Study. J Nanomed Nanotecho 4: 173. doi:10.4172/2157-7439.1000173

Copyright: (C) 2013 Shahoon H, et al. This is an open-access article distributed under the terms of the Creative Commons Attribution License, which permits unrestricted use, distribution, and reproduction in any medium, provided the original author and source are credited. 
Citation: Shahoon H, Hamedi R, Yadegari Z, Majd Hosseiny VA, Golgounnia P, et al. (2013) The Comparison of Silver and Hydroxyapatite Nanoparticles Biocompatibility on L929 Fibroblast Cells: An In vitro Study. J Nanomed Nanotechol 4: 173. doi:10.4172/2157-7439.1000173

Page 2 of 4

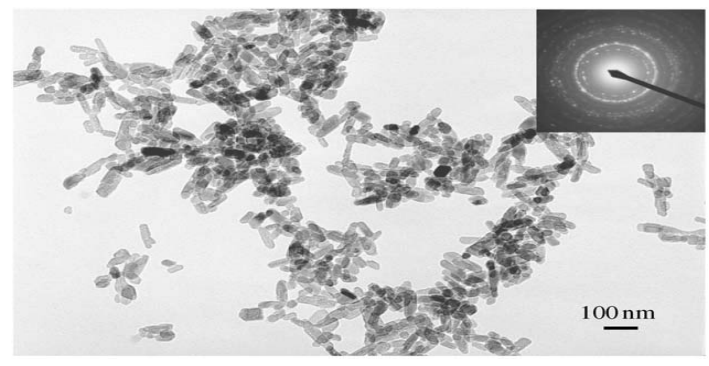

Figure 1: Transmission electron micrograph of nHA particles

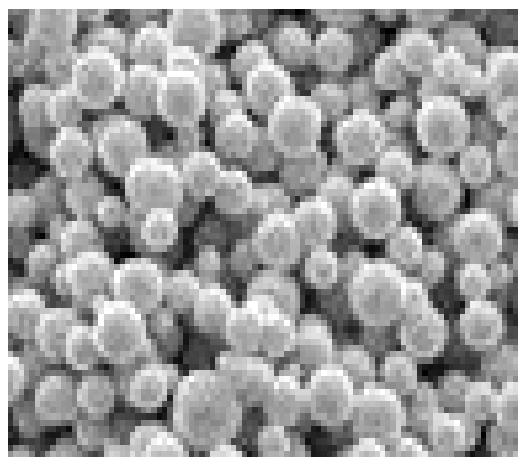

Figure 2: Transmission electron micrograph of nano silver particles.

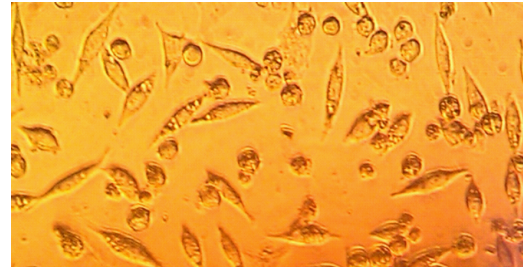

Figure 3: Microscopic image of L929 fibroblast cells cultured in flasks.

in order to cultivating the cells. We also added $100 \mathrm{IU} / \mathrm{ml}$ Penicillin (Sigma, USA) and $100 \mathrm{IU} / \mathrm{ml}$ Streptomycin (Sigma, USA) to sterilize the medium. To enrich the cultivating medium, 10\% FBS (GIBCO, USA) were added. The cell suspension was distributed in each well in triplicate on a 96 -well culture plate and cultured at $37^{\circ} \mathrm{C}$ in humidified air containing $5 \% \mathrm{CO}_{2}$.

\section{Exposure L929 fibroblast cells to nHA and nano silver particles}

10,000 fibroblast cells were exposed to $\mathrm{nHA}$ and nano silver particles at the following concentrations: 5, 10, 20, 30, 40, 50 ppm. For measuring the biocompatibility of these materials, MTT method was utilized after 24, 48, 72 hrs.

\section{Cell viability assay}

The viability of L929 fibroblast cells was assessed using the MTT (3-(4, 5-dimethylthiazol-2-yl)-2, 5-diphenyl tetrazolium bromide) assay. This Method outlines a simple assay to determine the viability/ number of colored product (in a mitochondria-dependent reaction) to which the cell membrane is impermeable [25]. Sample solutions were removed after incubation with the various nHA preparations and MTT was added at the concentration of $0.5 \mathrm{mg} / \mathrm{ml}$ in medium for $4 \mathrm{~h}$ at $37^{\circ} \mathrm{C}$. Dissolved MTT is converted to an insoluble purple formazan by cleavage of the tetrazolium ring by dehdrogenase enzymes. Cells were rinsed with PBS and $500 \mathrm{ml}$ of extracting solution $(0.04 \mathrm{M} \mathrm{HCl}$ in isopropanol) was added to each well so the water insoluble formazan can be solubilized. Plates were incubated for $15 \mathrm{~min}$ at room temperature to dissolve the dye and $200 \mathrm{ml}$ of dye solution was transferred to 96 well plates. Absorbance was measured at $570 \mathrm{~nm}$ (ASYS HiTech Expert plate reader) and cell viability was expressed as percent relative to the control.

\section{Results}

Results of this study showed that although the mean of L929 fibroblast cells' vitality exposing to nHA was decreased by increasing concentration and time elongation (Table 1) but ANOVA analyze indicated that there was no significant difference between groups $(\mathrm{p}>0.05)$.

Cytotoxicity percentages of L929 fibroblast cells and were shown in figure 4 for each concentration in all time durations. Noted that nHA at $50 \mathrm{ppm}$ concentration after $72 \mathrm{hrs}$ had the maximum percentage of cell's mortality (19.4\%).

Vitality of L929 fibroblast cells exposing to nano silver particles were the least after 24 hours, but the vitality of cells increased after 48 hours (Table 2) and ANOVA analyze indicated that there was significant difference between groups $(\mathrm{p}<0.05)$. Also the result showed concentrations over $20 \mathrm{ppm}$ within 24,48 hours are toxic to fibroblast cells and it was significant $(\mathrm{p}<0.02)$. However within 72 hours there are no significant findings in cells vitality $(\mathrm{p}>0.05)$.

Cytotoxicity percentages of L929 fibroblast cells were shown in figure 5 for each concentration in all time durations Noted that nano

\begin{tabular}{|l|c|c|c|}
\hline $\begin{array}{l}\text { Concentrations } \\
\text { of nHA }\end{array}$ & $\mathbf{2 4}$ hours & $\mathbf{4 8}$ hours & $\mathbf{7 2}$ hours \\
\hline $\mathbf{5}$ & $0.299 \pm 0.005$ & $0.295 \pm 0.009$ & $0.259 \pm 0.007$ \\
\hline $\mathbf{1 0}$ & $0.306 \pm 0.01$ & $0.300 \pm 0.005$ & $0.267 \pm 0.006$ \\
\hline $\mathbf{2 0}$ & $0.309 \pm 0.002$ & $0.297 \pm 0.003$ & $0.262 \pm 0.002$ \\
\hline $\mathbf{3 0}$ & $0.298 \pm 0.009$ & $0.299 \pm 0.009$ & $0.256 \pm 0.002$ \\
\hline $\mathbf{4 0}$ & $0.304 \pm 0.004$ & $0.295 \pm 0.007$ & $0.238 \pm 0.002$ \\
\hline $\mathbf{5 0}$ & $0.308 \pm 0.009$ & $0.295 \pm 0.005$ & $0.236 \pm 0.004$ \\
\hline
\end{tabular}

Table 1: Mean and standard deviations of vitality of L929 fibroblast cells after exposure to different concentrations of $\mathrm{nHA}$ at 24,48 and $72 \mathrm{hrs}$.

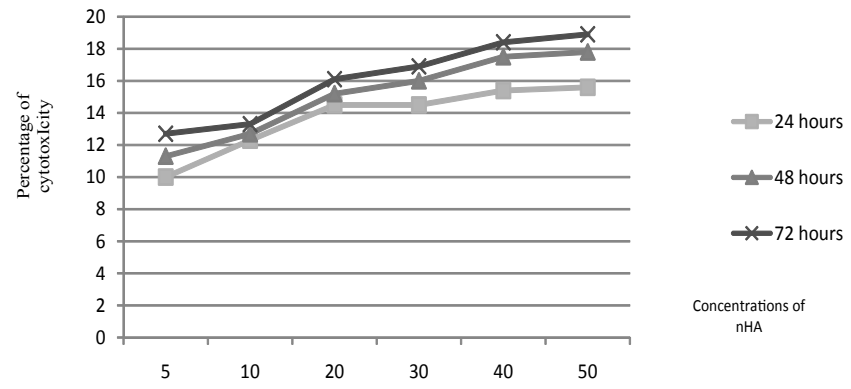

Figure 4: Comparisions of percentage of fibroblast cells' mortality exposing to nHA after 24,48 and 72 hrs. 


\begin{tabular}{|c|c|c|c|}
\hline $\begin{array}{l}\text { Concentrations } \\
\text { of nano silver }\end{array}$ & 24 hours & 48 hours & 72 hours \\
\hline 5 & $0.16 \pm 0.003$ & $0.18 \pm 0.003$ & $0.21 \pm 0.016$ \\
\hline 10 & $0.13 \pm 0.012$ & $0.16 \pm 0.002$ & $0.2 \pm 0.022$ \\
\hline 20 & $0.12 \pm 0.024$ & $0.16 \pm 0.013$ & $0.2 \pm 0.0005$ \\
\hline 30 & $0.05 \pm 0.001$ & $0.15 \pm 0.02$ & $0.18 \pm 0.04$ \\
\hline 40 & $0.06 \pm 0.0004$ & $0.15 \pm 0.02$ & $0.19 \pm 0.005$ \\
\hline 50 & $0.03 \pm 0.0003$ & $0.13 \pm 0.01$ & $0.19 \pm 0.043$ \\
\hline
\end{tabular}

Table 2: Mean and standard deviations of vitality of L929 fibroblast cells after exposure to different concentrations of nano silver particles at 24,48 and $72 \mathrm{hrs}$.

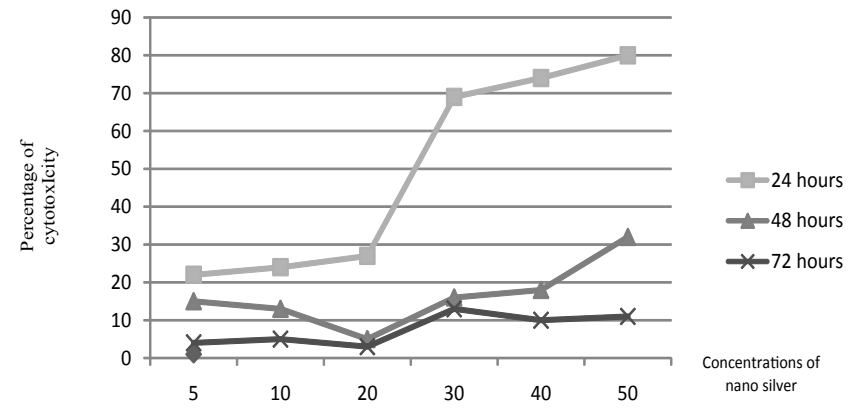

Figure 5: Comparisions of percentage of L929 fibroblast cells' mortality exposing to nano silver particles after 24,48 and $72 \mathrm{hrs}$.

silver particles at $50 \mathrm{ppm}$ concentration after $24 \mathrm{hrs}$ had the maximum percentage of cell's mortality (80\%).

\section{Discussion}

The results showed that the percentage of cells' mortality was elevated by increasing the concentration and duration of nHA exposure, no statistically significant difference was found between the groups ( $p>0.05)$ but the result showed nano silver particles at concentrations more than $20 \mathrm{ppm}$ and before 72 hours had toxic effects and it was significant $(\mathrm{p}<0.02)$.

Zhao et al. [25] studied the influence of HA nanocrystal at 10-100 ppm on osteoblasts proliferation after $24 \mathrm{hrs}$ by MTT method and found that this materials exhibit good biocompatibility and would be safe to be used. Also, Hsieh et al. [26] used culture of MC3T3-E1 osteoblast cells for evaluating toxicity of nHA particles and figured out that nHA particles have minimal toxicity on osteoblast cells. Our findings confirm the results of these studies and in the present study L929 fibroblast cells were used as samples.

Motskin et al. [27] studied the cytotoxicity of synthetic colloid and gel nHA at 31,62, 125, 250 and 500 ppm concentrations on Human Monocytes'-derived Macrophages (HMMs) by MTT assay and found gel preparation being the most toxic. Other preparations were also toxic but only at higher concentrations ( $>250 \mathrm{ppm})$. In this study we used the suspension of nHA and the cytotoxity was evaluated on L929 fibroblast cells [27].

Scheel et al. [28] evaluated the cytotoxicity of nHAparticles at 50, 100, 500, 1000 and 5000 ppm concentrations on RAW 264.7 macrophages and cells were analyzed for viability (MTT-test) after 18 and $42 \mathrm{hrs}$. Their results showed that up to concentrations of $500 \mathrm{ppm}$ cell viability was not considerably impaired by the test samples at both time points. The results of mentioned reports suggest nHA materials can be toxic and may inhibit proliferation.
Cao et al. [29] had done a research about biocompatibility of nano composite silver on L929 fibroblast cells, by use of 3-4-5 dimethyl thiazole test and 2-5 diphenyl tetras volume, and they found that nano composite silver is useful for cells division and increasing the cohesiveness of fibroblast cells.

The result from this research was different from our study that could result from the use of nano particles at Cao et al. [29] study as nano composite. Nano composite is two phase's material with polymer or metal or ceramic base, lead to change in their mechanical properties.

Zhang et al. [30] studied the citotoxicity of 6 types of nano particles with silver base, on L929 fibroblast cells, by MTT assay and result of this study showed that these particles didn't have any toxic effect in concentrations less than $25 \mathrm{ppm}$. Our findings confirm the results of this study and showed that nano silver concentration above $20 \mathrm{ppm}$ are toxic on fibroblast cells too.

Thus, nHA were more biocompatible rather than nanosilver particles on L929 fibroblast cells. But the main cause of nHA cytotoxicity on macrophages at concentrations up to $125 \mathrm{ppm}$ is probably phagocytosis of particles and releasing of calcium in cytoplasm of cells but fibroblast cells cannot phagocytosis the particles, so we can adjudicate that the degree of toxicity correlated strongly with the degree of uptake and it highly strongly suggests that cellular particle load is the main cause of cytotoxicity of nHA. However, differences in the physicochemical and structural characteristics between the various forms of $\mathrm{nHA}$ and nano silver particles may lead to differences in the properties and surface geometry, and surface chemistry which play a determinant role in biocompatibility. Therefore, development of novel nanoparticles for pharmacology, therapeutics and diagnostics must proceed in tandem with assessment of any toxicological and environmental side effects of these particles and further studies including histological and biological evidences, molecule reactions are required to determine the ultimate fate of the nHA and nano silver particles within the body.

\section{Acknowledgements}

This work was supported by a grant from Research Center at Shahed University of Medical Sciences and cellular molecular biology department of Shahid Beheshti University/dental faculty, Tehran, Iran.

\section{References}

1. Sintubin L, De Gusseme B, Van der Meeren P, Pycke BF, Verstraete W, et al (2011) The antibacterial activity of biogenic silver and its mode of action. Appl Microbiol Biotechnol 91: 153-162.

2. Liu J, Sonshine DA, Shervani S, Hurt RH (2010) Controlled release of biologically active silver from nanosilver surfaces. ACS Nano 4: 6903-6913.

3. Chaloupka K, Malam Y, Seifalian AM (2010) Nanosilver as a new generation of nanoproduct in biomedical applications. Trends Biotechnol 28: 580-588.

4. Sotiriou GA, Pratsinis SE (2010) Antibacterial activity of nanosilver ions and particles. Environ Sci Technol 44: 5649-5654.

5. Medina C, Santos-Martinez MJ, Radomski A, Corrigan OI, Radomski MW (2007) Nanoparticles: pharmacological and toxicological significance. $\mathrm{Br} J$ Pharmacol 150: 552-558

6. Krejci CB, Bissada NF, Farah C, Greenwell H (1987) Clinical evaluation of porous and nonporous hydroxyapatite in the treatment of human periodontal bony defects. J Periodontol 58: 521-528.

7. Kim JS, Kuk E, Yu KN, Kim JH, Park SJ, et al. (2007) Antimicrobial effects of silver nanoparticles. Nanomed Nanotech Biol Med 3: 95-101.

8. Morones JR, Elechiguerra JL, Camacho A, Holt K, Kouri JB, et al. (2005) The bactericidal effect of silver nanoparticles. Nanotechnology 16: 2346-2353.

9. Lee HY, Park HK, Lee YM, Kim K, Park SB (2007) A practical procedure for producing silver nanocoated fabric and its antibacterial evaluation fo biomedical applications. Chem Commun (Camb) 2959-2961. 
Citation: Shahoon H, Hamedi R, Yadegari Z, Majd Hosseiny VA, Golgounnia P, et al. (2013) The Comparison of Silver and Hydroxyapatite Nanoparticles Biocompatibility on L929 Fibroblast Cells: An In vitro Study. J Nanomed Nanotechol 4: 173. doi:10.4172/2157-7439.1000173

10. Vigneshwaran N, Kathe AA, Varadarajan PV, Nachane RP, Balasubramanya $\mathrm{RH}$ (2007). Functional finishing of cotton fabrics using silver nanoparticles. J Nanosci Nanotechnol 7: 1893-1897.

11. Kim K, Park SB (2008) Environmental Protection Agency. Petition for rulemaking requesting EPA regulate nanoscale silver products as pesticides; Notice of availability. J Nanotechnology 73: 644-646

12. Richter L, Charwat V, Jungreuthmayer C, Bellutti F, Brueckl H, et al. (2011) Monitoring cellular stress responses to nanoparticles using a lab-on-a-chip. Lab Chip 11: 2551-2560.

13. Kasaj A, Röhrig B, Zafiropoulos GG, Willershausen B (2008) Clinical evaluation of nanocrystalline hydroxyapatite paste in the treatment of human periodontal bony defects--a randomized controlled clinical trial: 6-month results. J Periodontol 79: 394-400.

14. Huber FX, Mcarthur N, Hillmeier J, Kock HJ, Baier M, et al. (2006) Void filling of tibia compression fracture zones using a novel resorbable nanocrystalline hydroxyapatite paste in combination with a hydroxyapatite ceramic core: first clinical results. Arch Orthop Trauma Surg 126: 533-540.

15. Grigor'ian AS, Grigor'iants LA, Podoinnikova MN (2000) A comparative analysis of the efficacy of different types of filling materials in the surgical elimination of tooth perforations (experimental morphological research). Stomatologi 79: $9-12$.

16. Gerlach KL, Niehues D (2007) Treatment of jaw cysts with a new kind of nanoparticular hydroxylapatite. Mund Kiefer Gesichtschir 11: 131-137.

17. Schwarz F, Bieling K, Latz T, Nuesry E, Becker J (2006) Healing of intrabony peri-implantitis defects following application of a nanocrystalline hydroxyapatite (Ostim) or a bovine-derived xenograft (Bio-Oss) in combination with a collagen membrane (Bio-Gide). A case series. J Clin Periodontol 33: 491-499.

18. Sheikh FA, Barakat NA, Kanjwal MA, Nirmala R, Lee JH, et al. (2010) Electrospun titanium dioxide nanofibers containing hydroxyapatite and silver nanoparticles as future implant materials. J Mater Sci Mater Med 21: 2551 2559.

19. Ferraz MP, Mateus AY, Sousa JC, Monteiro FJ (2008) Nanohydroxyapatite microspheres as delivery system for antibiotics: release kinetics, antimicrobial activity, and interaction with osteoblasts. J Biomed Mater Res A 81: 994-1004.
20. Matsumoto T, Okazaki M, Inoue M, Yamaguchi S, Kusunose T, et al. (2004) Hydroxyapatite particles as a controlled release carrier of protein. Biomaterials 25: 3807-3812.

21. Uchida A, Shinto Y, Araki N, Ono K (1992) Slow release of anticancer drugs from porous calcium hydroxyapatite ceramic. J Orthop Res 10: 440-445.

22. Zhou G, Li Y, Xiao W, Zhang L, Zuo Y, et al. (2008) Synthesis, characterization and antibacterial activities of a novel nanohydroxyapatite/zinc oxide complex. $J$ Biomed Mater Res 85: 929-937.

23. Jung WK, Koo HC, Kim KW, Shin S, Kim SH, et al. (2008) Antibacterial Activity and Mechanism of Action of the Silver Ion in Staphylococcus aureus and Escherichia coli. J ADA 74: 2171-2178.

24. Suchanek W, Yoshimura M (2004) Processing and properties of hydroxyapatitebased biomaterials for use as hard tissue replacement implants. J Mater Res 21: $94-117$.

25. Zhao Y, Zhang Y, Ning F, Guo D, Xu Z (2007) Synthesis and cellula biocompatibility of two kinds of HAP with different nanocrystal morphology. $J$ Biomed Mater Res B Appl Biomater 83: 121-126.

26. Hsieh MF, Li JK, Lin CA, Huang SH, Sperling RA, (2009) Tracking of cellula uptake of hydrophilic CdSe/ZnS quantum dots/hydroxyapatite composites nanoparticles in MC3T3-E1 osteoblast cells. J Nanosci Nanotechnol 9: 2758 2762

27. Motskin M, Wright DM, Muller K, Kyle N, Gard TG, et al. (2009) Hydroxyapatite nano and microparticles: Correlation of particle properties with cytotoxicity and biostability. Biomaterials 30: 3307-3317.

28. Scheel J, Weimans S, Thiemann A, Heisler E, Hermann M (2009) Exposure of the murine RAW 264.7 macrophage cell line to hydroxyapatite dispersions of various composition and morphology: assessment of cytotoxicity, activation and stress response. Toxic In Vitro 23: 531-538.

29. Cao XL, Cheng C, Ma YL, Zhao CS (2010) Preparation of silver nanoparticles with antimicrobial activities and the researches of their biocompatibilities. $J$ Mater Sci Mater Med 21: 2861-2868.

30. Zhang FQ, She WJ, Fu YF (2005) Comparison of the cytotoxicity in vitro among six types of nano-silver base inorganic antibacterial agents. Zhonghua Kou Qiang Yi Xue Za Zhi 40: 504-507. 